\title{
FRONTEIRAS LITORÂNEAS \\ NO CONCEITO DE SUJEITO EM PESQUISAS \\ SOBRE A SUBJETIVIDADE EM JOGO \\ NO ENSINO-APRENDIZAGEM DE LÍNGUAS
}

\author{
Carla Nunes Vieira Tavares \\ Universidade Federal de Uberlândia \\ Uberlândia - Minas Gerais, Brasil
}

\begin{abstract}
Resumo: Este trabalho pretende problematizar a relação de afetação do conceito de sujeito elaborado na psicanálise freudolacaniana em pesquisas com base na Análise do Discurso, conhecida no Brasil como AD de linha francesa, sobre a temática da relação sujeito-língua. Em especial, interroga pesquisas sobre o ensinoaprendizagem de línguas, em uma perspectiva discursiva, que enfocam tal temática. O artigo, primeiramente, aborda a leitura do conceito de sujeito nos estudos sobre o discurso; em seguida, analisa os desdobramentos teóricos e metodológicos que decorrem do comprometimento com tal conceito sob a perspectiva psicanalítica freudo-lacaniana; e, por fim, problematiza os limites da relação de afetação entre os campos da $A D$ e a psicanálise quanto a esse conceito. As considerações apontam para a necessidade de procedimentos de constituição e de análise de corpora que privilegiem a subjetividade em sua relação constitutiva com a linguagem.
\end{abstract}

Palavras-chave: Discurso. Sujeito. Língua.

\section{INTRODUÇÃO}

O título deste trabalho remete a uma metáfora utilizada por Lacan ((1971) 2003) no texto Lituraterra para enfatizar a possibilidade de conjugação de dois campos heterogêneos, resguardando-se uma relação de

\footnotetext{
* Doutora em Linguística Aplicada pela UNICAMP, e em Ciências da Linguagem pela Université de Franche-Comté, França. Email: carla.tav@uol.com.br
} 
descontinuidade. Tal me parece ser a relação entre a Análise do Discurso de linha francesa (AD) e a Psicanálise no que concerne ao conceito de sujeito. A complexidade de se levar a termo os desdobramentos que uma relação epistemológica como essa acarreta tem interrogado o pesquisador da linguagem, cujas questões de pesquisa convocam-no a pensar os movimentos subjetivos que causam um rearranjo da subjetividade em função do encontro-confronto com uma língua. Mais especificamente, refiro-me aos efeitos de uma possível relação do sujeito com o objeto de saber, neste caso, a língua a ser aprendida e/ou ensinada ${ }^{1}$ e da mediação dessa relação pelo professor. Abro um parêntese para indicar que a subjetividade é entendida, aqui, como a experiência que alguém faz de si, por meio da linguagem, e que resulta em um construto discursivo, passível de ser permanentemente (re)construído nas relações, a partir de elementos subjetivados. Não se confunde, portanto, com o conceito de sujeito, segundo a perspectiva psicanalítica, mas é afetado por ele, na medida em que é entendido como um construto maleável, dinâmico, responsável por fazer de alguém um ser particular no mundo. Esclareço, ainda, que a perspectiva teórica que embasa minhas considerações quanto às questões leva em conta aquilo que é da ordem de uma exterioridade à língua como constitutivo do discurso.

A reflexão teórica que proponho se justifica devido ao número crescente de pesquisas sobre ensino-aprendizagem de línguas que se ancoram teórico-metodologicamente nos pressupostos da AD. Do ponto de vista epistemológico, a AD propõe trabalhar e incluir a exterioridade nos estudos sobre o discurso, em especial os trabalhos de Pêcheux, que postulam a primazia da linguagem, permitem questionar a literalidade dos sentidos e mobilizam o conceito de sujeito dividido e, portanto, consideram a hipótese do inconsciente. Consequentemente, esgota-se a possibilidade de se pensar o sujeito como uma instância empírica e essencialista e a

\footnotetext{
1 Ressalto que me refiro tanto à língua designada "estrangeira" quanto à chamada de "materna", pois ambas representam a possibilidade de que se instaure uma outra discursividade a partir da qual o aluno possa se posicionar para ser enunciado e se enunciar. A língua dita materna, que se aprende na escola, não pode ser considerada língua primeira, pois, além de o aluno já chegar nesse contexto falando uma língua, esta não coincide com a ensinada na escola.
} 
subjetividade enquanto uma construção fixa e estável. Por exterioridade, refiro-me aos efeitos do ideológico, da historicidade, do social, e, neste trabalho em especial, ao efeito do inconsciente, estranho à univocidade lógica, mas que se deixa flagrar sub-repticiamente no discurso, indiciando o sujeito na/da enunciação. A partir dessa perspectiva teórico-metodológica, é possível incluir, nos estudos linguísticos, a consideração dos efeitos de sentido resultantes da tensão dos movimentos de representação de mundo que um sujeito empreende no decorrer da vida, levando-se em conta tanto os processos sócio-históricos quanto a clivagem do sujeito na constituição e na dispersão dos sentidos. Ressalto que limitarei minhas considerações ao que se convencionou chamar de terceira fase da AD proposta por Pêcheux, na qual os trabalhos se voltaram para as "formas linguístico-discursivas do discurso-outro [...], discurso de um outro, colocado em cena pelo sujeito, ou discurso do sujeito se colocando em cena como um outro; [para] a insistência de um 'além' interdiscursivo" (PÊCHEUX, (1983)1997, p. 316, grifo do autor).

Em trabalhos anteriores (TAVARES, 2007, 2009), propus que os pressupostos teóricos da $\mathrm{AD}$ constituem uma base epistemológica sobre a qual pode ser construído um percurso metodológico relevante para pesquisas que investigam o ensino-aprendizagem de língua estrangeira, visto que viabilizam a inclusão de variáveis não controláveis ou experimentáveis na discussão do processo. Consequentemente, seria possível contemplar os embates, os conflitos e a diferença não como algo a ser solucionado, mas como constitutivos do ensino-aprendizagem, na medida em que a mobilização do conceito de sujeito enquanto dividido e constituído na e pela linguagem implica um compromisso teórico com a consideração da subjetividade e com uma teoria de linguagem que a considera opaca e insuficiente para representar o mundo. Mais especificamente, os gestos de interpretação sobre um determinado corpus em uma pesquisa que pretende investigar a subjetividade daqueles que se encontram-confrontam com uma língua poderiam tomar o sujeito não só pelo que diz, mas no que $\mathrm{diz}^{2}$. Assim, os efeitos de sentido que esse dizer

\footnotetext{
${ }^{2}$ Sobre a especificidade que envolve a constituição de um corpus na perspectiva discursiva que se compromete com a Linguística da Enunciação, ver Agustini e Bertoldo (2011).
} 
produz poderiam indiciar pontos em torno dos quais a subjetividade dos envolvidos se ancora durante o processo e a relação que eles estabelecem ou não com a língua em questão (TAVARES, 2007).

Essa me parece ser uma questão de extrema relevância, em especial porque a visada discursiva sobre o processo de ensino-aprendizagem de uma língua possibilita encará-la como um objeto de saber que possa ser investido subjetivamente para que algo dele venha a se inscrever no sujeito. Em outras palavras, o processo implica uma tomada da palavra. Tomo esse termo emprestado de Lacan ((1969)1992), para me referir ao evento de inscrição subjetiva em uma discursividade, seja ela construída na língua materna ou estrangeira, de modo que alguém possa, a partir da palavra do Outro, ser enunciado e enunciar-se e produzir significações. Não se trata de um discurso corrente, ao qual o psicanalista se refere como sendo uma fala que não provoca efeitos, mas de uma produção enunciativa inserida numa lógica discursiva que produz laço social. Não me refiro, por essa expressão, a uma mera interação entre locutores, mas a uma relação de trabalho entre pares que rompe a barreira do discurso corrente reprodutor e é capaz de produzir algo novo justamente devido à lógica discursiva a partir da qual é tecida (LACAN, (1969)1992).

Entretanto, a visada discursiva sobre o ensino-aprendizagem de línguas pode suscitar questões sobre os efeitos desse evento na subjetividade que, a meu ver, demandam o aprofundamento da discussão sobre a relação epistemológica que se estabelece a partir da consideração do conceito de sujeito conforme lido da psicanálise freudo-lacaniana pela AD. Em um dos artigos citados anteriormente (TAVARES, 2007), defendi a ideia de que se trata de uma relação de atravessamento, que permite considerar nos gestos de interpretação de um corpus o que Pêcheux nomeou de efeito-sujeito. Presentemente, intenciono revisitar essa noção, pois acredito que ela seja mobilizada em trabalhos que investigam a subjetividade no ensino-aprendizagem de línguas na perspectiva discursiva. Objetivo explicitar as possibilidades teórico-metodológicas resultantes da consideração da instância do inconsciente nos trabalhos sobre ensinoaprendizagem de línguas e problematizar, a partir de alguns exemplos, os limites que se configuram na relação de afetação entre psicanálise, AD e os estudos sobre a linguagem. 


\section{A AD E O CONCEITO DE SUJEITO}

O ponto em comum a partir do qual foi possível estabelecer uma relação de afetação entre a $\mathrm{AD}$ e a Psicanálise é a premissa de que o sujeito é constituído pela linguagem e, por isso, não é causa nem origem de si mesmo. Consequentemente, o essencialismo e o idealismo encontram-se excluídos dessa conceituação.

Já na obra Semântica e discurso, Pêcheux ((1975)2009) voltou sua atenção para o funcionamento discursivo que permitiria que em uma dada formulação fosse possível produzir um efeito de unidade e de evidência que assinalaria o sujeito do discurso. Apoiando-se na noção freudiana de recalque, o autor abordou a ilusão constitutiva que permite a um enunciador ocupar a posição de sujeito de seu enunciado. Ele se refere a essa ilusão como fruto de dois esquecimentos que ocorrem concomitantemente, um indissociado do outro (chamados pelo autor de esquecimento no. 1 e 2). $\mathrm{O}$ sujeito "esquece" que não está na origem nem no controle dos sentidos em uma enunciação, visto que se encontra assujeitado às formações discursivas, ideológicas e às condições de produção do enunciado. Estas são responsáveis por assinalar ao sujeito uma posição discursiva que ele deve ocupar para ser, ilusoriamente, sujeito de seu enunciado, ao mesmo tempo em que determinam o que pode e deve ser dito naquele dado momento sócio-histórico. A evidência de um sujeito único, insubstituível e idêntico a si mesmo, portanto, é construída pela identificação às várias formações discursivas e por meio da interpelação exercida pelos processos socioideológicos.

A esse efeito que possibilita a construção de uma unidade egóica e, portanto, imaginária, a partir de uma ilusão subjetiva, Pêcheux nomeou de efeito-sujeito. Segundo Leite (1994, p. 27), essa conceituação enseja "um exame da subjetividade enquanto referida à relação especular com o semelhante, vale dizer, com o plano da identificação ao outro". Como consequência, a análise dos sentidos produzidos no dizer recai na relação 
entre simbólico e imaginário, com pouca referência ao real ${ }^{3}$. A análise das relações de paráfrases delineia uma matriz que determina os efeitos de sentidos produzidos por um sujeito, que estaria a ela identificado e que se colocaria, ilusoriamente, como origem e controlador dos mesmos. Segundo Leite (p. 27), "Muitas das considerações da questão da subjetividade na linguagem e no discurso referem-se a este plano e se sustentam em uma noção de Outro não-barrado". O efeito-sujeito aludido por Pêcheux, portanto, se remetido à psicanálise, se refere à instância do eu imaginário (o moi, segundo os estudos lacanianos). Neste ponto, é preciso lembrar que a instância do eu, na perspectiva psicanalítica, é responsável por prover uma unidade imaginária que constitui todo aquele que enuncia e que ela deriva da alienação do sujeito à linguagem. Tal instância se sustenta, justamente, na ilusão de que é possível a alguém saber algo de si e do mundo, de que este saber é original, de que o dizer reflete a intencionalidade daquele que fala. Sem esses "esquecimentos", para usar um termo pêcheutiano, ninguém jamais conseguiria tomar a palavra da posição de sujeito do enunciado.

Destaco um ponto em torno do qual Pêcheux desenvolve a elaboração da noção de efeito-sujeito: a presença e o efeito do Outro no discurso como presentificando uma alteridade radical. A alteridade como constitutiva do discurso foi mais amplamente estudada por Authier-Revuz (1998), quando defende que o discurso é heterogeneamente constituído e que o sujeito empreende diferentes modos de negociação para garantir um efeito de homogeneidade. Mas, segundo Leite (1995), Pêcheux já trabalha com esse pressuposto desde a leitura que fez da psicanálise através de Althusser. Ou seja, para enunciar-se enquanto "eu", o sujeito já está inscrito no simbólico e o faz a partir de uma relação imaginária com a "realidade". Nesse sentido, o Outro do campo da linguagem é anterior ao sujeito e o interpela a nele se inscrever para, a partir daí, enunciar-se e representar sua relação com o real por meio da construção de uma ilusão imaginária de unidade.

\footnotetext{
3 Refiro-me aos três registros propostos por Lacan como sendo responsáveis pela estruturação do funcionamento psíquico do sujeito.
} 
$\mathrm{Na} \mathrm{AD}$, esse Outro comparece fortemente (embora não somente) como sendo a história, a memória e a ideologia. Ou seja, ao falar, o eu está assujeitado ao campo do Outro e essa sujeição é que torna possível que alguém advenha como sujeito. Para a AD, então, interessa analisar

[...] como alguns significantes "tomam corpo" na história, prendemse a sentidos e se tornam signos para uma dada posição-sujeito de onde um sujeito enuncia em determinadas condições de produção, já interpelado pela ideologia, já falado pelo Outro (MARIANI, 2003, p. $66)$.

Configura-se que o efeito-sujeito na $\mathrm{AD}$ refere-se a uma posição no discurso que responde pelo assujeitamento ao Outro, que comparece na forma da interpelação ideológica em ação na história. A posição de onde alguém enuncia indicia as formações discursivas presentes no que diz, o que o torna inerentemente contraditório. Entretanto, o efeito de aparente homogeneidade do dizer se dá graças ao efeito-sujeito em funcionamento. Mariani (2003, p. 70) acrescenta:

O sujeito significa já afetado pelo Outro sem se dar conta do processo de retomadas e mudanças das significações no qual se encontra. [...] Ao dizer 'eu' desse lugar imaginário e identificado à formação discursiva que o domina, o sujeito materializa sua inserção na história, mostra um percurso de sentidos na língua e, ao mesmo tempo, se coloca à mercê do jogo dos significantes.

Entretanto, a insistência do inconsciente, que, pela via da repetição simbólica, fratura a frágil linearidade da cadeia discursiva e desestabiliza uma pretensa linearidade e unidade do enunciado, interpelou Pêcheux, evidenciando a divisão do sujeito e a barra que atravessa o campo do Outro. $\mathrm{O}$ trabalho permanente dos traços inconscientes resultantes da inscrição do significante na pulsação sentido/não sentido do sujeito dividido (PÊCHEUX; FUCHS, (1975)1997, p. 316, 317) fez o autor pensar as formas como a resistência em se deixar assujeitar comparecem na materialidade linguística. 
A título de evidenciar essa retomada, destaco uma retificação do texto de (1975)2009, no anexo 3 (escrito em 1979), em que o autor repensa os sentidos que o termo 'esquecimento' imprimiu à ilusão necessária para a tomada de uma posição-sujeito no discurso; e modaliza a noção de interpelação e de assujeitamento, enfatizando a impossibilidade de que esses processos sejam plenos, visto que são movidos por algo que rateia - a falta que funda o sujeito, que deriva do furo na linguagem. Assim, a resistência do sujeito em se assujeitar apareceria nos traços que indiciam o equívoco da linguagem, como "formas de aparição fugidias de alguma coisa 'de uma outra ordem', vitórias ínfimas que, no tempo de um relâmpago, colocam em xeque a ideologia dominante, tirando partido do seu desequilíbrio" (PÊCHEUX, (1979)2009, p. 278). Aquilo que resiste e aparece como falha, lapso, equívoco no dizer e quebra a pretensa linearidade discursiva se apresenta como um efeito do sujeito da enunciação. Neste momento da teorização pêcheutiana, a leitura do conceito de sujeito se aproxima da perspectiva psicanalítica quanto ao que essa propõe como sendo o sujeito do desejo e do gozo. Os gestos de interpretação da $\mathrm{AD}$, então, acolhem os modos de contenção da descontinuidade que se impõe no dizer pela insistência do registro do real da língua e os efeitos desse real no campo dos sentidos.

Segundo Riolfi (1994), as principais contribuições de Pêcheux em sua terceira fase da AD residem no fato de sua elaboração ter possibilitado pensar a impossibilidade de uma totalização de saber por uma teoria enquanto produtiva, a aceitação desse furo enquanto elemento fundamental para incluir um sujeito faltoso na estrutura atravessada pelo acontecimento, permitir operar com a categoria do real como contingente e, por conseguinte, encarar o não sentido como constitutivo do sentido. Nas palavras da autora (p. 83), a AD desta fase permite considerar "a relação que um sujeito entretém com suas palavras".

Percebe-se, portanto, que para a AD interessa analisar o funcionamento discursivo que possibilita ao enunciador se colocar como sujeito do que diz, considerando-se as condições sócio-históricas em que se dá esse dizer. De acordo com Mariani (2003, p. 61): 
O sujeito, para a análise do discurso, é uma posição material lingüístico-histórica produzida em meio ao jogo de contradições e tensões sócio-ideológicas. Assim, em uma dada análise, busca-se compreender o modo de produção de sentidos resultante das posições discursivas de sujeito constituídas.

\section{FRONTEIRAS DO CONCEITO E HORIZONTES AVISTADOS}

Como já assinalado, a perspectiva discursiva sobre o ensinoaprendizagem de línguas tem contribuído para incluir na análise do processo fatores da ordem da subjetividade dos envolvidos.

Primeiro, porque possibilita encarar o processo como uma possibilidade de (re)posicionamento discursivo, na medida em que o encontro-confronto com uma outra discursividade se configura como uma instância de alteridade a partir da qual alguém encontre (ou se confronte com) uma outra posição discursiva mediante a qual possa se contar, pressuposto caro à perspectiva discursiva abordada. Explicito aqui a pluralidade de sentidos do verbo "contar", que, nesse enunciado, remete ao narrar de si mesmo e ao ser contado dentre seus pares. Mesmo quando consideramos o ensino-aprendizagem da chamada língua materna, a alteridade pode se configurar, uma vez que a língua aprendida na escola não coincide com aquela falada pela criança que aí chega e que, para adentrar no mundo do conhecimento abalizado socialmente, precisa inscrever-se na discursividade em que esse mundo é enunciado ${ }^{4}$.

Segundo, porque enseja a problematização de sentidos cristalizados que se vinculam a representações de ensino-aprendizagem, de língua, de professores e de alunos, repercutindo para entender o processo como sempre incompleto, perpassado pelo conflito e pela diferença, atributos inerentes à relação que um sujeito pode estabelecer com um objeto. Os trabalhos embasados na perspectiva discursiva têm contribuído para interrogar a homogeneidade e o desejo por unidade e por uma solução direcionadora que normalmente perpassam a abordagem do tema.

\footnotetext{
4 Para uma problematização mais ampla sobre o questionamento da denominação materna/estrangeira, ver Coracini (2007), dentre outros.
} 
É preciso lembrar, no entanto, que a relação pedagógica estabelecida em um processo de ensino-aprendizagem se pauta, dentre outros elementos, em uma ação educacional agenciada pelo saber em jogo. Seu objetivo, via de regra, encerra um ideal educacional, qual seja, o de contribuir para a formação de indivíduos, bem como permitir a inserção deles em uma coletividade (FILLOUX, 1996). Consequentemente, o processo de ensinoaprendizagem pressupõe uma expectativa de movimentação ou deslocamento dos envolvidos em função da relação construída com o objeto de saber em jogo. Na perspectiva discursiva, tais movimentos não são considerados em termos do sucesso ou insucesso da ação, mas dos efeitos que ela pode ou não imprimir no sujeito e na subjetividade e na relação dialógica instaurada entre sujeito e objeto.

Encarar o ensino-aprendizagem de línguas na perspectiva discursiva descortina, a meu ver, a possibilidade de aprofundar a análise e a discussão desses efeitos, o que demanda voltar o olhar mais atentamente às relações entre sujeitos e entre sujeito e objeto. Refiro-me particularmente às operações de alienação, separação e identificação que se sucedem na vida de todos para que, de algum modo, traços do mundo em que vivemos e, consequentemente, dos objetos de saber sejam subjetivados. Lembro que a subjetivação opera a despeito da consciência, da reflexão ou da vontade e, portanto, seus efeitos não são perceptíveis no fio do dizer, mas na articulação do (não) dito com o dizer, nos indícios que resultam da interpelação do Outro sobre o sujeito.

A afetação da $\mathrm{AD}$ pelo conceito de sujeito da psicanálise representa uma possibilidade de investigação da subjetividade em jogo no ensinoaprendizagem de línguas, na medida em que permite incluir o Real da língua como elemento constitutivo da própria língua e considera o equívoco e a opacidade como inerentes à linguagem. Entretanto, a fim de acolher as questões sobre a subjetividade e os movimentos subjetivos que decorrem de um processo de ensino-aprendizagem, seria produtivo um maior compromisso com a premissa psicanalítica de que um sujeito é o efeito da intervenção de um significante na bateria de significantes (S1 - S2), ou seja, compreendê-lo como uma construção intervalar, sempre na relação entre 
dois significantes. De onde sugiro que os gestos de interpretação dos dizeres dos envolvidos no ensino-aprendizagem de línguas que se debruçam sobre aquilo que indicia a equivocidade na materialidade linguística não se apressem em reputar a esses indícios um efeito do sujeito da enunciação. Para que tal efeito tivesse a chance de se configurar seria preciso que o que faz furo no dizer interrogasse o interlocutor e o sujeito, enquanto efeito, pudesse (ou não) aparecer como resposta. Ainda assim, penso que o que poderia ser indiciado nas pesquisas em foco é da ordem dos efeitos que uma desestabilização na rede bem tecida de significantes podem causar na construção subjetiva.

Uma articulação mais ampla entre a $\mathrm{AD}$ e a psicanálise quanto à noção de discurso também pode se mostrar enriquecedora teóricometodologicamente. As seguintes citações evidenciam a possibilidade de aproximação teórica, embora cada campo tenha conferido à noção propósitos diferentes:

Destas três definições [de Foucault $]^{5}$ que retivemos de modo mais especial guardaremos essencialmente a noção de discurso como uma prática, resultante de um conjunto de determinações reguladas em um momento dado por um feixe complexo de relações com outras práticas, discursivas e não discursivas (MALDIDIER; NORMAND; ROBIN, (1976)1997, p. 82).

Os discursos [...] nada mais são do que a articulação significante, o aparelho, cuja mera presença, o status existente, domina e governa tudo o que eventualmente pode surgir de palavras. São discursos sem palavras, que vêm em seguida alojar-se neles (LACAN, (1969)1992, p. 158-159)

\footnotetext{
${ }^{5}$ As três definições aludidas na citação se referem às noções de discurso, prática discursiva e formação discursiva. A partir do anos 80 , portanto, o grupo de pesquisadores do discurso pautado nas propostas pêcheutianas explicita a filiação teórica à noção de discurso de Foucault, conforme o filósofo a havia proposto na obra Arqueologia do Saber ((1969)1986), nas seguintes palavras: "[Um discurso] é um conjunto em que se podem determinar a dispersão do sujeito e sua descontinuidade consigo mesmo. É um espaço de exterioridade em que se desenvolve uma rede de lugares distintos" (p.70).
} 
O discurso, em ambos os campos, é entendido como uma produção linguageira construída a partir de práticas discursivas. Tal construção congrega um conjunto de enunciados regulados sócio-historicamente mediante os quais alguém é chamado a ocupar uma posição para ser sujeito do que diz. Desse prisma, trata-se de uma estrutura que preexiste ao sujeito e que define e regulariza as práticas linguageiras e as relações humanas. Compreender o discurso como um conjunto de práticas que constrói discursivamente os objetos de que trata, modificando-se e modificando os domínios a que pertencem, bem como um dispositivo estrutural que assinala a um sujeito uma função enunciativa, distancia-se da noção que o reputa como a soma das proposições sobre um determinado objeto. Antes, a noção se compromete com a enunciação, dimensão em que se configuram as condições de produção de um enunciado, em que se encontram imbricados o sócio-histórico e o ideológico, bem como um saber resultante da cisão do sujeito, o do inconsciente.

Consequentemente, faz-se produtivo fazer operar o não sentido nas análises de corpora, vislumbrando modos de coleta de dados que possam cotejar manifestações do efeito do sujeito da enunciação e a pontuação possível quanto à sua posição subjetiva em relação ao objeto, configuradas pelo equívoco e/ou pela repetição e recorrência. A repetição e a recorrência são entendidas aqui como um retorno do mesmo, mas sempre com a instauração de um sentido outro e, portanto, pressupondo a diferença. Entretanto, enquanto a repetição, na visada da psicanálise, aponta para o que rateia na busca do sujeito por algo que tampone a falta que o constitui, e, assim, pode ser indiciada tanto no dizer como pelas posições-sujeito que os falantes ocupam; a recorrência se refere ao funcionamento parafrástico da linguagem, que permite traçarmos matrizes de significação, possíveis indiciadoras dos pontos de identificação que o sujeito instaura com o objeto.

Para tanto, parece-me necessário dar mais um passo e interrogar o alcance de alguns gestos de constituição de corpora e de certos procedimentos de análise que pretendem contemplar a questão da subjetividade na linguagem, em especial no que diz respeito a uma possível reconfiguração dela como resultado de alguma intervenção pedagógica. 


\section{4 À GUISA DE CONCLUSÃO, ALGUNS EXEMPLOS E CONSIDERAÇÕES}

Em uma relação pedagógica, por exemplo, tratar-se-ia de investigar os efeitos da mediação que deve acontecer entre aquele que demanda um saber e o objeto desse saber, bem como os efeitos sobre a subjetividade da relação do sujeito com esse objeto. Entrevejo nesse escopo investigativo a oportunidade de discutir os movimentos subjetivos que poderiam indiciar uma tomada de posição em relação ao processo de ensino-aprendizagem e em relação ao objeto. Em outras palavras, movimentos, indiciados na enunciação, que pudessem sinalizar um reposicionamento discursivo dos envolvidos no processo.

Para circunstanciar as fronteiras que apontei anteriormente, circunscrevo minhas considerações a um procedimento de análise muito recorrente nas pesquisas em foco neste artigo: a análise, sob a perspectiva discursiva, de representações dos envolvidos no ensino-aprendizagem de línguas.

Em grande número de trabalhos, considera-se que a representação responde por um gesto de interpretação do mundo por meio de sistemas de significação, é construída por meio de associações e jamais se refere a algo unitário, transparente ou unívoco. Ela é indiciada no dizer por meio do funcionamento parafrástico da linguagem, que pode remeter para o movimento metonímico do desejo constitutivo do sujeito de fazer sentido de si e de sua posição no mundo. A análise das representações permite perceber as reformulações em torno de um determinado objeto de discurso, ensejando uma certa condensação de sentidos que aponta para um imaginário a respeito desse objeto. A análise daquilo que é recorrente no dizer explicita a heterogeneidade discursiva, que precisa ser recalcada para que algo possa ser dito sobre um objeto de forma a produzir algum sentido. Para a AD, o trabalho de descrição regular do funcionamento discursivo do dizer enseja momentos de interpretação que expõem efeitos de identificação a filiações sócio-históricas e a redes de memória sobre o objeto do discurso (PÊCHEUX, (1983)1997. 
Porém, é preciso ressaltar que a análise das representações dos envolvidos em processos de ensino-aprendizagem coteja o registro do imaginário. Ou seja, a análise delineia um mapa de identificações que indicia os modos como as diferentes formações discursivas incidem na constituição do dizer, os modos como se articulam as redes de memória e como o sujeito se identifica a elas, o que, sem dúvida, traz inúmeras contribuições para problematizar o processo de ensino-aprendizagem de línguas. Percebe-se que o conceito mobilizado é o de efeito-sujeito, postulado por Pêcheux na terceira fase da $\mathrm{AD}$, conforme exposto no tópico 2. Contudo, acatar o que o próprio Pêcheux (1983)1997 preconiza quanto ao discurso, a saber, que "todo discurso marca a possibilidade de uma desestruturação-reestruturação dessas redes e trajetos" que o constituem, enseja ao pesquisador o questionamento quanto ao que pode causar a desestruturação das redes e esburacar, temporariamente, o mapa de identificações ao qual o sujeito se ancora para significar o mundo, assim como quais são os efeitos desse acontecimento na subjetividade.

Para tanto, parece-me necessário dar consequência ao não sentido que se presentifica na desestruturação, remetendo-o aos efeitos que ele pode (des)velar ou causar sobre a subjetividade daquele que enuncia, desde que este seja interpelado a se posicionar quanto a eles. Talvez ainda fosse preciso um maior comprometimento com a noção de Outro e encará-lo não só como um campo, mas como um lugar do qual o sujeito é interrogado e em relação ao qual é chamado a se posicionar. Lembro que o sujeito, para a psicanálise, é "um ato de resposta, uma resposta dada em ato" (ELIA, 2004, p. 41) e que essa resposta não se limita à prática psicanalítica, nem é dada, necessariamente, via dizer.

Cabe esclarecer, porém, que o inconsciente enquanto efeito de discurso - pois só se tem acesso a ele através das formações do inconsciente - tem decorrências distintas nos campos em questão. $\mathrm{Na}$ psicanálise, o inconsciente é o foco, na medida em que seus efeitos permitem dizer algo da verdade (sempre meia-verdade, como insistia Lacan) de um sujeito em relação ao desejo e ao gozo, ensejando um (re)posicionamento subjetivo. Já na perspectiva discursiva, o mesmo efeito acolhe inferências quanto ao que indicia da relação do sujeito com o objeto 
e/ou da subjetividade daquele que enuncia. Demanda do analista de discurso, portanto, gestos de interpretação que não engessem o sentido, mas o mantenham aberto à produção e à significação. $\mathrm{O}$ efeito do inconsciente, entretanto, não constitui o foco da análise e, sim, um dos elementos que atesta a impossibilidade de fechar os sentidos sobre um objeto, indicia a referência constante de um dizer a outro dizer e considera a subjetividade como inerente à produção discursiva.

Retomando as considerações sobre os trabalhos em tela, quando as perguntas de pesquisas sobre o ensino-aprendizagem de línguas se voltam para a relação entre sujeitos e entre sujeito-objeto não é apenas o dizer dos envolvidos que pode revelar algo da subjetividade que está em jogo no processo. As expressões faciais, a entonação dos enunciados, as respostas corporais resultantes do encontro-confronto com o objeto e/ou com a barra ao gozo que decorre da função do professor (e, algumas vezes, do entrevistador) podem indiciar uma ruptura no discurso, permitindo (des)velar-se algo do sujeito enquanto efeito.

Ademais, poderia mostrar-se produtivo considerar as impressões do pesquisador/entrevistador quanto ao que ele observa. Não me refiro a tomar as anotações ou os diários, que normalmente constituem instrumentos secundários de pesquisa, como evidências de um dizer ou como um discurso que ratifica um determinado imaginário. Pelo contrário, concordo com Agustini e Bertoldo (2011), que pensam a coleta de dados como parte de uma enunciação em construção, em que a todo momento efeitos da ordem da singularidade que comparece na subjetivação de traços do objeto podem irromper. Essa postura metodológica convida a incluir na constituição de um corpus os modos pelos quais o pesquisador se deixou afetar e a aprofundar modos pelos quais o conceito de sujeito como efeito na e da enunciação pode ser mais amplamente operacionalizado em pesquisas sobre a relação sujeito-língua.

Esses indícios, constitutivos das condições de produção de enunciados, podem indicar a resposta do sujeito quanto ao que desestrutura sua posição discursiva, mas normalmente não são cotejados nas análises que empreendemos na perspectiva discursiva. Levá-los em conta, a meu ver, permitiria intensificar o tratamento que é dado à subjetividade nos estudos sobre a linguagem que a tem como vértice fundamental. 


\section{REFERÊNCIAS}

AGUSTINI, C.; BERTOLDO, E. A constituição de corpora em linguística da enunciação. In: SILVEIRA, E.M. (Org). As bordas da linguagem. Uberlândia: EDUFU, 2011. p. 121-133.

AUTHIER-REVUZ, J. Palavras incertas: as não-coincidências do dizer. Campinas, SP: Editora de Unicamp, 1998.

CORACINI, M. J. Nossa língua: materna ou madrasta ? In: . A celebração do outro: arquivo, memória e identidade - línguas (materna e estrangeira), plurilinguismo e tradução. Campinas, SP : Mercado de Letras, 2007. p.135-148. ELIA, L. O conceito de sujeito. Rio de Janeiro : Zahar, 2004.

FILLOUX, J. Du contrat pédagogique : le discours inconscient de l'école. Paris: L'Harmattan, 1996.

FOUCAULT, M. (1966). As palavras e as coisas: uma arqueologia das ciências humanas. São Paulo: Martins Fontes, 2000.

1986.

. (1969). A arqueologia do saber. Rio de Janeiro, RJ: Forense Universitária,

LACAN, J. Subversão do sujeito e dialética do desejo no inconsciente freudiano.

In: . (1960). Escritos. Rio de Janeiro: Jorge Zahar, 1998. p. 807-842. . (1969). O seminário livro 17: o avesso da Psicanálise. Rio de Janeiro, RJ: Jorge Zahar, 1992.

Zahar, 2003. . (1971). Lituraterra. In: . Outros escritos. Rio de Janeiro: Jorge

LEITE, N. Psicanálise e Análise do Discurso: o acontecimento na estrutura. Rio de Janeiro: Campo Matêmico, 1994.

MALDIDIER, D.; NORMAND, C.; ROBIN, R. (1976) Discurso e ideologia: bases para uma pesquisa. In: ORLANDI, E. (Org). Gestos de leitura: da história no discurso. Campinas, SP: Editora Unicamp, 1997. p.67-102.

MARIANI, B. Subjetividade e imaginário linguístico. Linguagem em (Dis)curso, Tubarão, SC, v. 3, Número Especial, p. 55-72, 2003.

PÊCHEUX, M.; FUCHS, C. (1975). A propósito da análise automática do discurso: atualização e perspectivas. In: GADET, F. e HAK, T. Por uma análise automática do discurso: uma introdução à obra de Michel Pêcheux. 3. ed. Campinas, SP: Editora Unicamp, 1997. p.163-252.

PÊCHEUX, M. (1975). Semântica e discurso: uma crítica à afirmação do óbvio. 4. ed. Campinas, SP: Editora Unicamp, 2009. 
. (1979). Só há causa daquilo que falha ou o inverno político francês: início de uma retificação. In: PÊCHEUX, M. Semântica e discurso: uma crítica à afirmação do óbvio. 4. ed. Campinas, SP: Editora Unicamp, 2009. p. 269-281. 1997. . (1983). Discurso: estrutura ou acontecimento. Campinas, SP: Pontes,

RIOLFI, C. R. O discurso que sustenta a prática pedagógica: formação de professor de língua materna. 1999. 361f. Tese (Doutorado em Linguística) Instituto de Estudos da Linguagem, Universidade Estadual de Campinas, Campinas, 1999.

TAVARES, C. N. V. Psicanálise e Análise do Discurso: atravessamentos e desdobramentos para as noções de sujeito e sentido. In: FERNANDES, C.A; SANTOS, J. B. C. (Orgs.). Percursos da Análise do Discurso no Brasil. São Carlos: Claraluz, 2007. p. 119-129.

. Ressonâncias discursivas: uma proposta de análise de dados em uma pesquisa sobre aprendizagem de língua estrangeira. Horizontes (EDUSF), v. 27, p. 105-114, 2009.

Recebido em: 26/11/12. Aprovado em: 15/08/13.

Title: Coastal frontiers in the concept of subject in researches on the subjectivity involved in teaching and learning languages

Author: Carla Nunes Vieira Tavares

Abstract: This work intends to discuss the relation of affectation between Freudian-Lacanian Psychoanalysis and Discourse Analysis - known in Brazil as French AD - specially the concept of the subject as elaborated in Psychoanalysis. It focuses mainly on researches interested in teaching-learning languages from a discursive perspective. First, the article approaches the understanding of the concept by the studies of discourse, analyzes the theoretical and methodological consequences of the relation between psychoanalysis and $A D$, and problematizes the limits of the psychoanalytical concept of the subject employed by the studies of discourse concerning the concept of the subject. The article points out the need for procedures of corpora constitution and analysis that value the subjectivity in its constitutive relation with language.

Keywords: Discourse. Subject. Language. 
Título: Fronteras litoráneas en el concepto de sujeto en investigación sobre la subjetividad en juego en la enseñanzaaprendizaje de lenguas

Autora: Carla Nunes Vieira Tavares

Resumen: Este trabajo pretende problematizar la relación de afectación del concepto de sujeto elaborado en el psicoanálisis freudo-lacaniana en investigación con base en el Análisis del Discurso, conocida en el Brasil como AD de línea francesa, sobre la temática de la relación sujeto-lengua. En especial, interroga pesquisas sobre la enseñanza-aprendizaje de lenguas, en una perspectiva discursiva, que enfocan tal temática. El artículo, primeramente, aborda la lectura del concepto de sujeto en los estudios sobre el discurso; enseguida, analiza los despliegues teóricos y metodológicos que resultan del comprometimiento con tal concepto bajo la perspectiva psicoanalítica freudo-lacaniana; $y$, por fin, problematiza los límites de la relación de afectación entre los campos del AD y el psicoanálisis sobre ese concepto. Las consideraciones apuntan para la necesidad de procedimientos de constitución y de análisis de corpora que privilegien la subjetividad en su relación constitutiva con el lenguaje.

Palabras-clave: Discurso. Sujeto. Lengua. 